\title{
STEPPIN' INTO THE FUTURE: CONNECTING BIPOC YOUTH TO STEM CAREERS
}

\author{
Jessica V. Forrester, Ph.D. Candidate, University of Minnesota, forre151@umn.edu \\ Lesa M. Covington Clarkson, Ph.D., Associate Professor, University of Minnesota, covin005@umn.edu \\ Elena A. Contreras Gullickson, Ph.D., Director of STEM Education, Harvest Best \\ Academy, cont0013@umn.edu
}

\begin{abstract}
Exposure to science, technology, engineering and mathematics (STEM) careers is essential for urban education in order to diminish deficit-based assumptions about who can succeed in STEM.

Prepare2Nspire (P2N) acts as an extracurricular tutoring outlet for in-school mathematics learning as well as an opportunity for youth to become exposed to STEM careers through various methods. First, undergraduate mentutors of color represent a number of STEM academic majors. Second, P2N invites STEM professionals of color to discuss how they use various mathematics skills within their career. The purpose of introducing students of color to underrepresented college students and STEM professionals is to motivate participants to visualize themselves within these career fields and strive for excellence.
\end{abstract}

\section{Program Overview}

Prepare2Nspire $(\mathrm{P} 2 \mathrm{~N})$ is a mathematics tutoring program dedicated to supporting underrepresented middle and high school scholars of color. The mission of P2N is to: 1. develop mathematics content knowledge, communication skills, and community and 2. create a STEM pipeline for underrepresented urban youth to post-secondary opportunities. The cascading tutoring-mentoring model of P2N allows undergraduate "mentutors" (mentors and tutors) to share personal experiences, content knowledge, and life advice with youth "mentutees" (mentees and tutees). In addition, P2N also serves as an environmental influence on students' understanding and curiosity in STEM careers (Blustein et al., 2012). Two methods utilized within the program are the strategic hiring of STEM undergraduate mentutors and the invitation of STEM professionals as guest speakers, both of which allow middle and high school participants to envision themselves within STEM careers.

P2N's undergraduate mentutors represent a number of STEM academic majors, ranging from mathematics education to chemical engineering. Mentutors intentionally describe the mathematics skills they use within their majors and how that is connected to the content youth participants are currently learning in school. In addition, P2N invites STEM professionals of color to discuss how they use various mathematics skills within their day-to-day tasks. These professionals were intentionally chosen because of their close relationship with STEM and their firsthand knowledge about career resilience and college readiness. Both mentutors and mentutees have reflected on the impact of the guest speakers, stating how they were able to visualize how mathematics knowledge can be applied in real-world situations. In addition, program participants' college entrance exams' mathematics scores increased significantly. Some of those participants earned entrance into an R1 institution and are majoring in STEM fields. The combination of undergraduate STEM mentutors and STEM guest speakers not only fulfills P2N's mission of creating a STEM pipeline for underrepresented youth, but also serves as an outlet for urban youth to strive for academic excellence in K-12 and higher education.

\section{References}

Blustein, D. L., Barnett, M., Mark, S., Depot, M., Lovering, M., Lee, Y., Hu, Q., Kim, J., Backus, F., DillonLieberman, K., \& DeBay, D. (2012). Examining urban students' constructions of a STEM/career development intervention over time. Journal of Career Development, 40(1), 40-67.

https://doi.org/10.1177/0894845312441680 